under 1 year old were vaccinated in The Gambia ${ }^{10}$ or in 1-15 year olds in Thailand. ${ }^{11} \mathrm{~A}$ further trial in infants is underway in Tanzania as this is the age group in Africa most at risk. While the concept of combining epitopes from different antigens and stages is a good one, this particular peptide is unlikely to be used outside South America, and even here will probably be superseded.

\section{Multiple antigen-epitope-gene approach}

The multiple antigen-epitope-gene approach to malaria vaccine development is widely perceived as the only way to achieve good antiparasitic and disease immunity. An important element of such an approach is likely to be an immune response to the sexual cycle that begins with the male and female gametocytes produced in the blood and is completed within the feeding mosquito. The acquired sexual stage immunity prevents mosquitoes becoming infected and, in model infections, it is possible to induce a very strong transmission blocking immunity with sexual stage antigens expressed by gametes or by post-fertilisation ookinetes. One small safety and immunogenicity phase I clinical trial has been done so far with a recombinant form of Pfs 25, the dominant post-fertilisation surface antigen of $P$ falciparum. Such a vaccine could be used alone in some low endemic situations or in combination with other vaccines or other control measures, when it would serve particularly to reduce the transmission of vaccine or drug resistant mutants. ${ }^{12}$

Seven $P$ falciparum antigens, three pre-erythrocytic, three asexual blood stage, and one sexual stage have been expressed simultaneously in recombinant form in an attenuated vaccinia virus called NYVAC 7 ; the first clinical trial with it has been done. DNA vaccines giving expression of CSP and other pre-erythrocytic stage antigens, which have given promising results in animal studies, will also soon be tested clinically. ${ }^{13}$

What can be expected in the next five to 10 years? A fairly safe prediction is that no vaccines will go into control programmes, although the need for these increases progressively. However, alongside the continuing basic research there are now organised attempts to develop what we have in concert with the pharmaceutical industry and to prepare field trial centres. The absolute requirement is for long and sustained investment.

\section{GEOFFREY A T TARGETT}

Professor, Department of Medical Parasitology,

London School of Hygiene and Tropical Medicine,

London WC1E 7HT, United Kingdom

1 Hoffman SL, ed. Malaria vaccine development: a multi-immune response approach. Washington, DC: ASM Press, 1996:310.

2 Jones TR, Hoffman SL. Malaria vaccine development. Clin Microbiol Rev 1994;7:303-10.

3 Nardin EH, de Olivera GA, Calvo-Calle JM, Nussenzweig RS. The use of multiple antigen peptides (MAPs) in the analysis and induction of protective immune responses against infectious diseases. Adv Immunol 1995;60: $105-49$.

4 Rodriguez M, Li S, Murato K, Rodriguez D, Rodriguez JR, Bacik I, et al. Influenza and vaccinia viruses expressing malaria $C D 8+T$ and $B$ cell epitopes. F Immunol 1994;153:4636-49.

5 Stoute JA, Slaoui M, Heppner DG, Momin P, Kester KE, Desmons P, et al. A preliminary evaluation of a recombinant circumsporozoite protein vaccine against Plasmodium falciparum malaria. $N$ Engl f Med 1997;336: $86-91$

6 Aidoo M, Valvani A, Allsopp CEM, Plebanski M, Meisner SJ, Krausa P, et al. Identification of conserved antigenic components for a cytotoxic T lymphocyte-inducing vaccine against malaria. Lancet 1995;345:1003-7.

7 Smith JD, Chitnis CE, Craig AG, Roberts DJ, Hudson-Taylor DE, Peterson DS, et al. Switches in expression of Plasmodium falciparum var genes correlate with changes in antigenic and cytoadherent phenotypes of infected erythrocytes. Cell 1995;82:101-10.

8 Holder AA. Preventing merozoite invasion of erythrocytes. In: Hoffman SL, ed. Malaria vaccine development: a multi-immune response approach. Washington, DC: ASM Press, 1996:77-104.

9 Amador R, Aponte JJ, Patarroyo ME. Development and field testing of the synthetic SPf66 vaccine. In: Hoffman SL, ed. Malaria vaccine development: a multi-immune response approach. Washington, DC: ASM Press, 1996:22948.

10 D'Alessandro U, Leach A, Drakeley CJ, Bennett S, Olaleye BO, Fegan GW, et al. Efficacy trial of malaria vaccine SPf66 in Gambian infants. Lancet 1995;346:462-7.

11 Nosten F, Luxemburger C, Kyle DE, Ballou WR, Wittes J, Eh Wah, et al. Randomized double-blind placebo-controlled trial of SPf66 malaria vaccine in children in northwestern Thailand. Lancet 1996;348:701-7.

12 Kaslow DC. Transmission-blocking vaccines. In: Hoffman SL, ed. Malaria vaccine development: a multi-immune response approach. Washington, DC: ASM Press, 1996:181-227.

13 Hoffman SL, Franke ED, Hollingdale MR, Druilhe P. Attacking the infected hepatocyte. In: Hoffman SL, ed. Malaria vaccine development: a multiimmune response approach. Washington, DC: ASM Press, 1996:35-75.

\title{
Is proficiency testing in cervical cytology proficient?
}

The proficiency test in cervical cytology may not be proficient, whether aimed at assessing individuals or laboratories as a whole, according to arguments from Dr C J R Stewart in a recent issue. ' Stewart's article follows a recent editorial on the same subject in Cytopathology $y^{2}$ and comes at a time when the draft guidelines for the NHS cervical screening programme (NHSCSP) are being revised for proficiency testing. Stewart's views, and those of Slater, ${ }^{2}$ reflect widespread scepticism about the way proficiency testing is carried out in the UK. Indeed, the British Society for Clinical Cytology and the Royal College of Pathologists had rejected the original draft guidelines, although supporting the need for some form of external quality assessment.

In an article referred to by Stewart, Valente says candidly that one of the goals of proficiency testing is to "weed out the incompetent", although he points out that there is no evidence that proficiency testing improves laboratory performance. ${ }^{3} \mathrm{He}$ also says that "common sense would indicate that the recognition of accepted diagnostic criteria is a valid measure of competence" and that "we must not lose sight of the education role of proficiency testing". ${ }^{3}$ Stewart suggests that internal quality control, accreditation, and comparison of performance and outcome might equally or even better be able to identify poor performance. Is an external assessment needed as well?

Stewart must be justified in saying that there is no evidence that mortality from cervical cancer is affected by proficiency testing. Laboratory performance would have to be uniformly substandard for a long time to be reflected in mortality, which is difficult to compare in small populations. More to the point, he says that proficiency does not reflect laboratory false negative rates. Sensitivity of primary screening is proportional to the number of abnormalities known to be present ${ }^{4}$ and would be expected to be high in a set of 10 slides almost half of which were known to be abnormal. Sensitivity of primary screening can be monitored by re-screening negative slides, but ultimately 
depends on accurate checking and reporting in the laboratory, and can therefore only be carried out as a component of internal quality control. Seeding test slides into routine work is impractical: experienced screeners, trained as they are to detect rare events in cervical smears, would undoubtedly recognise the test slides before even putting them under the microscope.

Yet screeners need to know, for their own self confidence, that they are able to recognise the full spectrum of cytological abnormalities, and can separate negative from inadequate, and low from high grade dyskaryosis. Furthermore, heads of departments need an objective assessment of the tendency of their screeners and biomedical scientists to over or underreport using standardised case material. They also need to be aware of any diagnostic blind spots that would take a long time to show up through rapid review. By its nature, proficiency testing identifies only extreme examples of poor performance in primary screening. This is a positive advantage, leading to well deserved reassurance most of the time. Even without being a test of primary screening sensitivity, proficiency testing for cytology screeners is important, particularly if an educational role can be introduced.

Proficiency testing is a rather better test for pathologists, which is probably the reason that it is us, rather than members of the National Association of Cytologists, who are loudest in criticising the tests. If it is to be used to identify poor performance, it would not be much use if all the abnormal cell groups were clearly and accurately marked on the slides. A pathologist needs to be able to examine the whole slide, identify cell groups that may have been missed, and make his or her own mind up about the presence or absence of significant abnormality. The high proportion of abnormal slides in the proficiency testing set is nearer routine practice for a pathologist than for a screener although a mixture of appropriately and inappropriately marked slides in addition to unmarked ones could make it more reflective of normal practice.

Without some form of external quality assurance or proficiency testing how could poor performance be detected early enough for remedial action to be taken without compromising the career of the person concerned? It must be better to have an objective assessment, with previously agreed protocols, than relying on the much more difficult methods of comparing reporting rates, reviewing reported work, and other investigations that can be highly damaging to all concerned.

Proficiency testing could better reflect routine practice by not excluding borderline and inadequate tests, which account for a considerably greater percentage of laboratory results than all grades of dyskaryosis combined. An external test that included the complete spectrum of cytological change, assessed by correlation with a majority verdict of a panel of cytologists (as well as by correlation with histology and follow up as appropriate) could go a long way towards providing a test that was educational for all grades of staff-as well as providing a test that could detect gross degrees of discordance.

Stewart has aired some reasonable objections to current methods of proficiency testing, and rightly suggests that a revised scheme should be subjected to evaluation and analysis of its intended benefits before being adopted. Perhaps the NHSCSP will develop a revised test that is more acceptable, better than the equally widely criticised tests used in the USA, and worthy of a screening programme that has been so successful in preventing invasive cervical cancer and reducing its mortality.

AMANDA HERBERT

Cytology Section, Histopathology Department,

Southampton General Hospital,

Tremona Road,

Southampton SO16 4XY, UK

1 Stewart CJR. Is the proficiency test in cervical cytology proficient? $\mathcal{F}$ Clin Pathol 1997;50:450-2.

2 Slater DN. Quality assurance in cervical cytopathology-time for a more evidence-based approach. Cytopathology 1997;8:75-8.

3 Valente PT. Government mandated cytology proficiency testing: time for reality testing. Diagn Cytopathol 1994;10:105-6.

4 Fowkes FGR. Diagnostic vigilance. Lancet 1986;i:493-4.

Applications or requests for further information about the post should be sent to: Mrs Alex Williamson, BMJ Publishing Group, BMA House, Tavistock Square, London WC1H 9JR. Tel: 0171383 6069, Fax 01713836668 and e-mail: 100302.1411@compuserve.com 